\title{
Inadimplência: Um estudo com usuários de cartão de crédito em Belo Horizonte/MG
}

\author{
Defaults: A study with credit card users in Belo Horizonte / MG
}

Ana Claudia da Silva ${ }^{1}$; Bianca Campos Xavier ${ }^{2}$.

\author{
${ }^{1}$ E-mail: ana.claudia-silva@outlook.com \\ Centro Universitário Metodista Izabela Hendrix \\ (CEUNIH) \\ ${ }^{2}$ E-mail: bianca.campos.xavier@gmail.com \\ Centro Universitário Metodista Izabela Hendrix \\ (CEUNIH)
}

Resumo: O presente estudo procurou identificar quais as causas de inadimplência de usuários de cartão de crédito, considerando a população de Belo Horizonte para esta análise; o trabalho transcorreu por assuntos como sistema financeiro nacional, os principais mercados financeiros, cartão de crédito, endividamento, comportamento do consumidor e planejamento financeiro. A metodologia utilizada quanto aos fins foi descritiva e quanto aos meios foi realizada uma pesquisa de campo. Foi utilizada uma amostra não probabilística de 100 pessoas, sendo escolhidas por julgamento, estas responderam a um questionário para o levantamento das informações. Com isto consistiu um embasamento para notar alguns comportamentos comuns dos inadimplentes e analisar como tais atitudes afetam para o encaminhamento da inadimplência de fato. Demonstra que a educação financeira constitui uma força crucial para auxiliar na diminuição deste quadro cada vez mais frequente, sua disseminação e usabilidade mais acessível e compreendida, tende a criar uma sociedade onde exista um equilíbrio entre o poder de compra e o quanto podem consumir.

Palavras-chave: Cartão de crédito; Endividamento; Planejamento Financeiro Pessoal.

Abstract: The present study seeks to identify the causes of delinquency of credit card users, considering the population of Belo Horizonte for this analysis; the work is carried out by subjects such as the national financial system, the main financial markets, credit card, indebtedness, consumer behavior and financial planning. The methodology used for this purpose was a descriptive field research. We used a non-probabilistic sample of 100 people, being chosen by judgment, they answered a questionnaire to collect information. This consisted of a baseline to note some common behaviors of the defaulters and to analyze how such attitudes affects the referral to the defaults. It demonstrates that financial education is a crucial force in helping to reduce this more and more frequent picture, its more accessible and understood dissemination and usability, tends to create a society where there is a balance between purchasing power and how much can be consumed.

Keywords: Credit card; Indebtedness; Financial planning. 


\section{pontěditora}

\section{1 - Introdução}

Apesar dos benefícios do cartão de crédito, existe também outro lado da utilização dele, que envolve o seu uso não adequado, transformando um benefício em desvantagem, devido ao descontrole do usuário, por adquirir dívidas que não tem condições de pagar, o tornando assim um inadimplente.

No último ano, 2017, o Portal de Notícias G1 apontou que o índice de inadimplência com cartão de crédito aumentou apesar da redução do rotativo, assim como indicou a classe D e E como sendo $80 \%$ da população encontrada no quadro de endividamento com cartão de crédito (LAPORTA, 2017a; LAPORTA, 2017b).

Hoje em dia os cartões estão em alta no mercado e é considerado o meio de pagamento preferido entre os brasileiros quando se trata de compra parcelada, a grande questão é que se percebe que a democratização do crédito, principalmente para as classes menos favorecidas ainda é algo que estes não sabem lidar, o que tornasse um risco, levando a uso indiscriminado do crédito (SPC BRASIL, 2018b).

Desta forma o objetivo deste trabalho foi identificar quais são as causas que levam uma pessoa ao endividamento por uso de cartão de crédito, usando como base para estudo pessoas residente na cidade de Belo Horizonte. Os objetivos específicos consistiram em:

- Descobrir comportamentos de compras comuns dos inadimplentes.

- Analisar como este meio de pagamento influencia a vida financeira de seus usuários.

- Propor um método de organização das contas com o intuito de auxiliar as pessoas a saírem da inadimplência.

O estudo relacionado neste trabalho mostrou-se importante devido a grande parte da sociedade a qual atinge, que querem entender sobre este caso, enxergando melhor o problema de modo a perceber a proporção da inadimplência atual, como a prevenir e a solucionar, utilizando métodos e implementações apresentadas por meio da educação financeira. Deste modo o trabalho visa agregar conteúdo informativo as pessoas para auxilio na melhor qualidade financeira pessoal. 


\section{2 - Referencial Teórico}

O referencial teórico deste trabalho tem como objetivo expressar quais as áreas relacionadas ao problema para a melhor compreensão da importância do mesmo.

A inadimplência ocasionada por uso de cartão de crédito lidera o ranking na pesquisa da CNC (2018). A causa dessa situação deve-se a multifatores, como poderá ser analisado mediante o desenvolvimento do trabalho. Para iniciar a análise deste nicho, o trabalho irá transcorrer sobre alguns aspectos que levam a melhor abrangência do que se destina, a saber, das causas de inadimplência dos belo horizontinos em relação à utilização do cartão de crédito; tendo uma linha de pesquisa que enfoca tanto no comportamento consumidor, ou seja, no âmbito comportamental dos usuários de cartão, como a visão do papel que a educação financeira pode influenciar, como medida de solução para este estudo.

\subsection{Sistema Financeiro Nacional}

Segundo Assaf Neto (2012, p.72), "O Sistema Financeiro Nacional (SFN) é constituído por um conjunto de instituições financeiras públicas e privadas que atuam por meio de diversos instrumentos financeiros, na captação de recursos, distribuição e transferência de entre os agentes econômicos”. O autor ainda menciona qual o órgão máximo do Sistema Financeiro Nacional, aquele que sua função básica é a definir como será o funcionamento do mesmo, formulando toda sua política de moeda e crédito da economia, tratando dos interesses econômicos e sociais, este órgão é o Conselho Monetário Nacional (CMN).

Atrelados ao CMN têm-se como órgãos normativos também o Banco Central do Brasil (BACEN) e a Comissão de Valores Mobiliários (CVM), juntos essas três instituições integram o subsistema normativo do SFN, que possui a incumbência pelo funcionamento do mercado e suas instituições (ASSAF NETO, 2012). Assaf Neto (2012, p. 72) ainda declara qual o principal órgão fiscalizador do mercado financeiro:

\footnotetext{
O Banco Central é o principal órgão executivo do $\mathrm{CMN}$, atuando principalmente como um organismo fiscalizador do mercado financeiro, gestor do sistema financeiro e executor da política monetária do governo. A Comissão de Valores Mobiliários, cuja atuação encontrase também diretamente vinculada ao Conselho Monetário Nacional, tem por responsabilidade básica o controle e o fomento do mercado de valores mobiliários (bolsa de valores). Dessa forma, a atuação da CVM abrange três importantes segmentos financeiros do mercado: instituições financeiras, companhias de capital aberto emitentes de títulos e valores mobiliários e investidores.
} 
As transações realizadas de recursos financeiros entre investidores e captores são concretizadas por meio de intermediários, ou seja, por instituições financeiras. Como afirma Gitman (2017, p. 33):

\begin{abstract}
As instituições financeiras atuam como intermediários, canalizando a poupança de indivíduos, empresas e governos para empréstimos ou investimentos. Muitas instituições financeiras pagam, direta ou indiretamente, juros sobre recursos depositados; outras prestam serviços em troca de tarifas (por exemplo, contas correntes pelas quais os correntistas pagam taxas de serviço). Algumas instituições financeiras aceitam depósitos de poupança de seus clientes e emprestam esse dinheiro a outros clientes ou empresas; outras investem a poupança de seus clientes em ativos remunerados, como imóveis, ações e títulos; e há quem faça as duas coisas. As instituições financeiras são obrigadas pelo governo a atuar de acordo com as diretrizes regulatórias.
\end{abstract}

Os principais clientes das instituições financeiras são as pessoas físicas, as empresas e os governos. Todo valor que é depositado nas instituições financeiras pelos clientes gera o montante dos recursos que esta obtém. No caso de pessoas físicas estas tanto depositam, fornecendo fundos às instituições como também tomam emprestados, ou seja, utilizam os recursos da instituição em forma de empréstimos. Vale ressaltar que apesar disto, pessoas físicas no geral são consideradas fornecedores líquidos, pois ainda poupam mais do fazem empréstimos (GITMAN, 2017).

Já as empresas também realizam depósitos de seus recursos nas instituições financeiras, sendo feitos principalmente em contas correntes de bancos comerciais. As empresas são tomadoras de empréstimos, mas ao contrário das pessoas físicas são considerados, demandantes líquidos de fundos, pois ainda fazem mais empréstimos do que poupam.

Os governos guardam nos bancos comerciais, fundos temporariamente ociosos, alguns tipos de pagamentos de impostos e à previdência social. Não fazem empréstimos diretamente das instituições financeiras, apesar de que quando um título do governo é vendido elas, neste caso são tomadas um empréstimo de maneira indireta. Assim como as empresas, os governos são considerados no geral como demandantes líquidos de fundos, pois também fazem mais empréstimos do que poupam.

Desse modo as principais instituições financeiras existentes que operam no mercado são os bancos comerciais, as associações de poupança e empréstimos, as cooperativas de crédito, as caixas econômicas, as seguradoras, os fundos de investimento e os fundos de pensão. 


\title{
2.1.1 - Mercado Financeiro
}

Conforme Assaf Neto (2012, p.77) em relação ao mercado financeiro, ele menciona que:

\begin{abstract}
Para tomar suas decisões financeiras de investimento e financiamento, as empresas necessitam das instituições do mercado financeiro. Esses mercados vêm assumindo enorme importância nos últimos tempos principalmente em razão do alto crescimento dos negócios no mundo, e da globalização da economia. $\mathrm{O}$ volume de recursos demandado nos mercados financeiros elevou-se bastante, e os instrumentos financeiros (títulos e valores mobiliários) negociados tiveram de acompanhar esse crescimento.
\end{abstract}

Para Gitman (2017, p. 35),

Os mercados financeiros são ambientes nos quais os fornecedores e os demandantes de fundos podem negociar diretamente. Enquanto as instituições financeiras concedem empréstimos sem o conhecimento direto dos fornecedores de fundos (poupadores), nos mercados financeiros os fornecedores sabem a quem seus fundos foram emprestados ou onde foram investidos.

Os chamados mercados financeiros entraram no mundo globalizado, emanando em todas as economias do mundo, por uma grande quantidade e variações de títulos negociados. Neste meio, os intermediários financeiros e as corporações, se mantem mais suscetível ao risco. Os intermediários financeiros são instituições que realizam as mediações de recursos entre agentes econômicos; estes captam recursos disponíveis de pessoas físicas e empresas com possibilidade de poupança, e os alocam para financiar necessidades de consumo de pessoas físicas e de investimento para empresas.

Existem dois meios pelo qual as empresas podem levantar fundos para investimento. De acordo com Assaf Neto (2012, p.77)

As empresas podem levantar recursos para investimentos através de fontes internas e fontes externas. Os recursos internos das empresas são identificados no volume retido de seus lucros, ou seja, na parcela do resultado líquido que não foi paga ao acionista na forma de dividendos. Os recursos gerados internamente não costumam ser suficientes para suprir toda a demanda de capital para investimento. 


\title{
pontěditora
}

Já Gitman (2017, p.35) define estas formas da seguinte maneira:

\begin{abstract}
Para levantar fundos, as empresas podem usar colocações privadas ou ofertas públicas. Uma colocação privada envolve a venda de uma nova emissão de valores mobiliários diretamente a um investidor ou grupo de investidores, como uma seguradora ou fundo de pensão. A maioria das empresas, contudo, levanta fundos por meio de uma oferta pública de valores mobiliários, que é a venda de títulos de dívida ou ações ao público em geral.
\end{abstract}

Um grupo de instituições formam os mercados financeiros, estes agem de modo a atender os interesses de tomadores de recursos, em junção com os aplicadores, tornando os recursos disponíveis para toda a economia. Ainda para Assaf Neto (2012), o mercado financeiro possui quatro subdivisões na intermediação financeira, são elas os: mercado monetário, mercado de crédito, mercado de capitais e mercado cambial. Gitman (2017), por sua vez menciona apenas o mercado monetário e o mercado de capitais como sendo os dois principais mercados financeiros.

\section{2 - Cartão de Crédito}

Como afirma o Banco Central do Brasil (2013, p.25), "Crédito é uma fonte adicional de recursos que não são seus, mas obtidos de terceiros (bancos, financeiras, cooperativas de crédito e outros)". Existem várias modalidades de créditos sendo o cartão uma delas; este possui a finalidade de proporcionar ao seu usuário uma alavancagem no consumo com aquisição de bens e mercadorias com maior facilidade e um prazo para o seu eventual pagamento (KUNKEL; VIEIRA; POTRICH, 2015).

Para Cerbasi (2004, p. 105): "Cartões de crédito são instrumentos de organização financeira, e a grande vantagem de seu uso está na concentração do pagamento das contas logo após o dia do recebimento do salário". Em um estudo solicitado pela Associação Brasileira de Cartões de Crédito e Serviços (ABECS) à Tendências Consultorias em 2011, mostra que o crescimento das vendas mediante cartões de crédito, está em plena expansão no Brasil. A preferência por este meio de pagamento dá-se pelas vantagens oferecidas, sendo estas, pagamento de todas as despesas com prazo, parcelamento, conveniência, praticidade em não precisar está com dinheiro em espécie, ou aguardar ter todo o montante para realização das suas compras. 


\section{pontěditora}

Isto também se deve a melhoria de renda dos consumidores nos últimos anos e também o acesso ao crédito beneficiando principalmente as pessoas de baixa renda, que obtiveram maior poder de compra neste caso. Com isso tanto os consumidores quanto os estabelecimentos ganham, pois enquanto um lado tem esta maior disponibilidade de comprar, ou seja, crédito para isso, o comércio por sua vez te um aumento de vendas, que se torna benéfica, pois já não tem tanta circulação de cheques que muitas vezes são entregues sem fundos, a inadimplência é controlada, visto que ele recebe da financeira do cartão o valor, que é para ele assegurado, e caso do não pagamento do cliente, este estará em débito com a administradora de seu cartão de crédito.

O país como um todo se beneficia com a utilização de cartões, devido o maior controle sobre as vendas pelo governo, afim de arrecadações de impostos, diminuindo as inconstâncias causadas pelas atividades informais. Para usar como exemplo na economia a utilização do meio de pagamento com cartões é um dos responsáveis pelo aumento das taxas de crescimentos dos Produtos Internos Brutos (PIB) (ABECS, 2011). No último balanço sobre a utilização, meios eletrônicos de pagamentos, realizada por Fernando Chacon (2017) para a ABECS, mostram que o valor transacionado por cartão de crédito teve um aumento de 12,4\% em relação a 2016, sendo em reais em 2016 o valor de R\$ 749,7 bilhões enquanto em 2017 este valor ficou em R \$ 842,6 bilhões. Foi analisada também a frequência da utilização do cartão, 96\% utilizam cartão todo o mês, $55 \%$ utilizam pelo menos um dia da semana e 58\% usam o parcelamento lojista todo mês. Houve também o aumento de compras não presenciais com cartão de crédito e quase $80 \%$ dos usuários o utilizam para realizar compras on-line sendo cerca de R\$ 167,6 bilhões movimentados aumento de 16,5\% em relação a 2016. Em 2017 o cartão também ganhou como a modalidade preferida para pagamento pelos brasileiros ultrapassando pela $1^{\mathrm{o}}$ vez o valor de compras realizado por quantia de saques e cheques compensados, estes respectivamente ficaram com movimentação de $\mathrm{R} \$ 1,31$ trilhões e R \$ 751 bilhões, enquanto o valor de compras por cartão de crédito ficou em R\$1,36 trilhões (CHACON, 2017).

Analisando os dados acima é possível verificar a importância do cartão de crédito para a economia do país e os impactos causados em sua utilização; como seu crescimento em utilização vem sendo cada vez maior, representando uma modalidade de pagamento dentre as mais utilizadas.

Apesar das suas vantagens, os usuários de cartão de crédito, em sua maioria parece não

$\mathrm{e}^{3}$ - Revista de Economia, Empresas e Empreendedores na CPLP | Volume 4 | Número 2 


\section{pontěditora}

saber como utilizar da melhor forma esta modalidade de crédito. Para que haja uma compreensão de o que leva o consumidor a tornar um benefício em algo que complica bastante sua vida financeira, é importante que se observe o comportamento do consumidor.

\subsection{2 - Órgãos de proteção ao crédito}

Os dois principais órgãos de proteção ao crédito utilizados em relação ao cadastro de pessoa física são o Sistema de Proteção ao Crédito (SPC) e a Serasa Experian. O SPC Brasil consiste em um órgão disponível para os associados da CDL de seu estado, onde dados dos consumidores das empresas associadas em todo país são compartilhados entre si, formando uma rede de informações seguras, auxiliando na concessão de crédito. Quando um consumidor entra em inadimplência, as empresas podem formalizar um registro de débito e um dos serviços oferecidos pelo SPC é de envio uma carta informativa ao consumidor, contendo o valor do débito; e também o de encaminhar a carta com o boleto tendendo a quitação por parte do cliente; sendo a diminuição de inadimplência, retorno financeiro, desenvolvimento econômico, são vantagens propostas pelo SPC aos seus usuários, que chegam a 1,2 milhão em todo país (SPC BRASIL, 2018a).

Já a Serasa Experian é responsável pela maior base de dados da América Latina, fornecendo relatórios precisos, reconhecida pelo Código de Defesa do Consumidor como uma entidade de caráter público (Lei 8.078, artigo 43, parágrafo $4^{\circ}$ ). Atua como apoio a empresas e consumidores nas decisões de crédito, dentre outras soluções como gestão de riscos, marketing e certificação digital. A Serasa Experian trabalha com soluções de que diminuem riscos de crédito, fraude, renegociação de dívidas (SERASA EXPERIAN, 2018).

Assim como o SPC, a Serasa também envia comunicados ao consumidor informando sobre seu débito e tentando reaver o valor devido. A diferença entre os dois é que o SPC é financiado pelas Câmaras de Dirigentes Lojistas e os dados são fornecidos aos associados da mesma, enquanto a Serasa Experian é uma sociedade anônima criada em parceria com associações bancárias. 


\section{pontěditora}

\section{3 - Endividamento}

Segundo Maia (2007), a adimplência possui uma função social importante, pois o cumprimento das dívidas confere ao mercado um retorno de capital, fazendo com isso que a economia tenha um bom desempenho, gerando empregos e políticas de créditos com maior flexibilidade. Ao contrário, ou seja, o inadimplemento gera impacto que atinge esses setores e traz prejuízos para a sociedade como o todo.

De acordo com Kunkel, Vieira e Potrich (2015), o comprador que utiliza o cartão como opção de pagamento, não necessariamente se torna um inadimplente; o ocorrido se concretiza a partir do dado momento que aquele usuário utiliza e deixa de pagar seus compromissos dentro do prazo estipulado; incidindo juros sobre a dívida no cartão, desse modo o endividamento no cartão de crédito pode ser compreendido como o saldo devedor remanescente após o pagamento da fatura mensal. Desse modo deixa explícito que a inadimplência ocorre quando ao ser ultrapassado o prazo para pagamento da compra realizada, neste há a incidência de juros, estes que são definidos e variados de acordo com a política da administradora do cartão.

Quanto à incidência de juros pela falta do pagamento, concorda Assaf Neto (2012, p. 80) que os juros podem ser entendidos como o preço pago pelo aluguel do dinheiro, ou seja, o valor que deve ser pago pelo empréstimo de um capital." "Evidentemente, quanto maior o risco de inadimplência do devedor, ou seja, quanto mais incapaz ele se mostra de efetuar os pagamentos de juros e principal nas datas pactuadas, mais alta se apresenta a taxa de juros exigida da operação" (ASSAF NETO, 2012, p. 81).

Um dos principais fatores que influenciam no aumento dos juros é a inflação, definida por Assaf Neto (2012, p. 81) como "uma elevação persistente nos preços de bens e serviços de uma economia, provocando a corrosão do poder aquisitivo da moeda". O autor também não deixa de considerar o fato que outro que influenciam na taxa de juros é os riscos conjunturais, que considera o ambiente político, econômico, social e cambial.

A Câmara dos Dirigentes Lojistas de Belo Horizonte (CDL/BH), aponta que a inadimplência de pessoas físicas aumentou $0,19 \%$ na comparação de janeiro 2017 com dezembro de 2016, e comparando o mês de janeiro de 2017/2016, o crescimento na inadimplência dos belo horizontinos foi de 2,88\%; sendo este resultado reflexo do aumento de taxa de desemprego, da inflação e diminuição de renda (CDL/BH, 2017). Certifica-se então que um dos fatores que contribui para o aumento da inadimplência são os resultados econômicos do país; apesar de uma condição econômica desfavorável 
que contribui para o alto endividamento, são demais situações e atitudes que este trabalho procura descobrir para responder como um indivíduo chega a tal situação e como pode este sair dela.

\section{4 - Comportamento do consumidor}

De acordo com Froemming et al. (2009, p. 19), “Comportamento do Consumidor concentra seus estudos para entender como as pessoas pensam e agem no suprimento de suas necessidades e desejos por meio da atividade do consumo". O fato de compreender como o consumidor se comporta, traz menção de como este reage no ato da utilização de seus recursos para aquisição de suas compras. Dentro da administração de finanças já existe um estudo voltado para isto, o chamado Finanças Comportamentais, o que Assaf Neto (2012, p.45) define desta forma:

\footnotetext{
Finanças comportamentais é um campo de estudo da Teoria de Finanças relativamente novo, tendo apresentado maior crescimento a partir da década de 80. Tem por objetivo básico estudar como os indivíduos, na vida econômica real, interpretam as informações recebidas e tomam as decisões de investimentos.
}

De acordo com o autor, essa disciplina também conhecida como Economia Comportamental procura conhecer vários aspectos psicológicos no processo de tomada de decisões financeiras, considerando inclusive os aspectos de irracionalidade.

A área de finanças pode ser conhecida por considerar bastante o lado racional em relação à tomada de decisões, as finanças comportamentais por sua vez, já se preocupa com a reação dos indivíduos diante de suas decisões financeiras e como suas predisposições psicológicas de cada um deles afeta seu comportamento. Esta disciplina objetiva-se a demonstrar que o indivíduo não se comporta sempre segundo os princípios da racionalidade, mas que aspectos psicológicos e sociológicos também possuem influência na avaliação econômica (ASSAF NETO, 2012).

Analisando estas afirmações para que as causas de inadimplência sejam levantadas, é importante o conhecimento de como os usuários do cartão de crédito se comporta em relação as suas compras. 


\section{5 - Planejamento Financeiro}

A falta de planejamento financeiro tem sido apontada como uma das causas para que os consumidores acabem caindo no endividamento, como publicou a $\mathrm{CDL} / \mathrm{BH}$ "a falta deste tem trazido muitos problemas as famílias, pois elas não têm o hábito de organizarem suas contas” (BASTOS, 2017). De acordo com Cerbasi (2004 p. 34),

\footnotetext{
O planejamento financeiro tem um objetivo muito maior do que simplesmente não ficar no vermelho. Mais importante do que conquistar um padrão de vida é mantê-lo, e é para isso que devemos planejar. Os maiores benefícios dessa atitude serão notados alguns anos depois, quando a família estiver usufruindo a tranquilidade de poder garantir a faculdade dos filhos ou a moradia no padrão desejado, por exemplo.
}

O autor também diz que por falta de conhecimento as pessoas tendem a pensar que para que se faça um planejamento financeiro é necessário obter ajuda de especialistas com ferramentas muito elaboradas; porém este equivoco se relaciona a muitos não terem domínio e predisposição de lidar com números e tabelas, afinal a educação financeira não é uma realidade em escolas brasileiras de todos os níveis. Porém, as ferramentas que são utilizadas para um planejamento financeiro utilizam-se de meios básicos e que podem ser compreendidas com a matemática do ensino médio. Se este ensino fosse difundido nas escolas com ações práticas do cotidiano de como lidar com dinheiro no âmbito familiar, provavelmente as pessoas já ingressariam em seu primeiro emprego com planos de independência financeira e maior domínio de uma boa utilização do seu dinheiro (CERBASI, 2004). O autor ainda menciona que:

É notório o fato de que, para enriquecer, é preciso aprender a gastar. Sua riqueza não depende do que vocês ganham, mas sim de como gastam. Alguns pontos são essenciais no planejamento financeiro; controle de gastos; estabelecimento de metas, disciplina com investimentos, ajustes referentes à inflação e mudanças na renda, administração do que se conquistou (CERBASI, 2004, p. 60).

Com base neste tópico, torna possível compreender sobre a importância de um planejamento financeiro, como uma medida de controlar melhor as contas, pode consequentemente evitar um possível endividamento. Pois o indivíduo ao ter consciência de como gastar pode otimizar o seu consumo, utiliza de maneira coerente tanto seu cartão, ou outra modalidade de crédito, sem contrair dívidas pelas quais não 


\title{
pontěditora
}

consiga cumprir o seu pagamento em dia, o que pode o levar a inadimplência.

\section{3 - Metodologia}

Quanto aos fins foi utilizada a pesquisa descritiva por se tratar de uma pesquisa que busca descobrir como ocorre determinado fato, com uma maior clareza a respeito de sua natureza e suas características, conforme afirma os autores:

\begin{abstract}
A pesquisa descritiva observa, registra, analisa e correlaciona fatos ou fenômenos (variáveis) sem manipulá-los. Procura descobrir maior precisão possível, a frequência com que um fenômeno ocorre, sua relação e conexão com outros, sua natureza e suas características. Busca conhecer as diversas situações e relações que ocorrem na vida social, política, econômica e demais aspectos do comportamento humano, tanto do indivíduo tomado isoladamente como de grupos e comunidades mais complexas (CERVO; BERVIAN; SILVA, 2006, p. 61).
\end{abstract}

Quanto aos meios foi realizada uma pesquisa de campo. Devido ser um tipo de pesquisa que busca obter informações de um determinado problema em que se procura respostas, comprovação de hipóteses e relações entre fenômenos (MARCONI; LAKATOS, 2009). Deste modo foram os tipos de pesquisas aplicadas neste trabalho para atingir seu objetivo em descobrir as causas de inadimplência de usuários de cartão de crédito em Belo Horizonte.

O universo de uma pesquisa consiste no grupo de pessoas, animais ou objetos que representem um total de indivíduos que tenham características semelhantes para o estudo (CERVO; BERVIAN; SILVA, 2006). Este trabalho considerou como seu universo pessoas físicas residentes da cidade de Belo Horizonte, que conta com uma população de cerca de 2,5 milhões de habitantes, segundo dados do IBGE (2017). A amostra por sua vez é uma parte que representa uma população, onde se realiza uma coleta de dados com determinado número de indivíduos, que garanta a representatividade do universo. A amostra deste trabalho considerou como critério 100 pessoas, da cidade de Belo Horizonte e os selecionados foram escolhidos por forma de julgamento, pois precisavam ser estes usuários de cartão de crédito, que estavam ou já estiveram inadimplentes.

A técnica de coleta de dados que foi utilizada para este trabalho considerou os dados primários obtidos através de questionário estruturado. Questionário é um instrumento de 


\section{pontěditora}

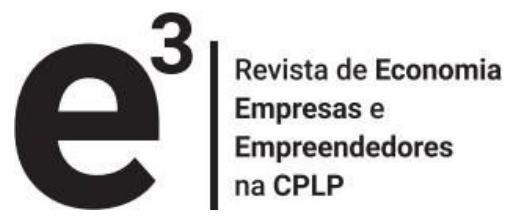

coleta de dados, constituído por uma série ordenada de perguntas, que devem ser respondidas por escrito, e sem a presença do entrevistador.

[...] Junto com o questionário deve-se enviar uma nota ou carta explicando a natureza da pesquisa, sua importância e a necessidade de obter respostas, tentando despertar o interesse do recebedor, no sentido de que ele preencha e devolva o questionário dentro de um prazo razoável (MARCONI; LAKATOS, 2009, p. 203).

O questionário compreendeu uma série de perguntas fechadas e de múltipla escolha, que quantificou os resultados da pesquisa. Foi realizado um pré-teste antes da aplicação da própria pesquisa, para certificar sobre a existência de algum erro de colocação das perguntas, clareza e compreensão das mesmas, tendo margem para realizar as devidas correções que forem necessárias.

Para a análise dos dados desta pesquisa foi considerada uma abordagem quantitativa, pois se embasou através de dados numéricos para conhecer o perfil, as atitudes, o comportamento dos entrevistados, chegando às causas que levam estes ao endividamento. Foi realizada, tabelas e gráficos utilizando o programa Excel da Microsoft Office, para detalhamento das informações obtidas.

\section{4 - Resultados e discussão}

A pesquisa foi realizada no período de 01/07/2018 à 10/08/2018 e foram aplicados os questionários aos moradores de Belo Horizonte, com o intuito de conhecer o perfil, as atitudes, o comportamento dos entrevistados, buscando as causas que levam estes ao endividamento por cartão de crédito. Participaram do estudo 100 pessoas que utilizam cartões de créditos e já ficaram ou são inadimplentes. Os dados demográficos apontam que $58 \%$ da amostra constituem pessoas do sexo feminino e $41 \%$ do sexo masculino. Em se tratando de faixa etária, 55\% da amostra compreende a idade entre 25 a 35 anos, $22 \%$ possui entre de 36 a 50 anos, $17 \%$ entre 18 a 24 anos e $4 \%$ acima de 50 anos.

No que diz respeito à renda mensal tem-se 57\% com renda acima de 1 salário mínimo até 3 salários mínimos, 25\% possui renda acima de 3 salários mínimos até 6 salários mínimos, $12 \%$ até um salário mínimo e apenas $4 \%$ com renda superior a 6 salários mínimos. No que se refere ao motivo da utilização do cartão de crédito para pagar suas compras, a maioria dos pesquisados $(51 \%)$ afirmou que usa o cartão de crédito por falta 


\section{pontěditora}

de dinheiro no ato da compra, 27,9\% declarou que usa o cartão de crédito devido ao prazo para o pagamento, entretanto $15,4 \%$ informou que o principal motivo para usar o cartão é a comodidade.

No gráfico 1 exibe a quantidade de cartão de crédito por pessoa.

\section{Gráfico 1 - Quantidade de cartões de crédito}

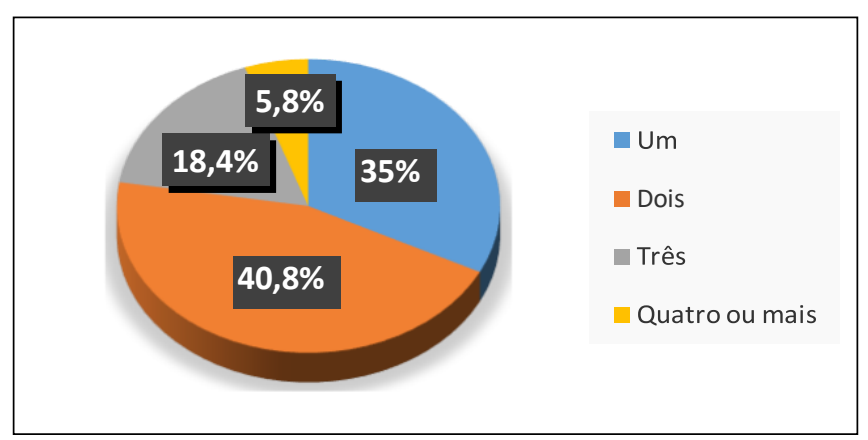

Fonte: Dados da pesquisa (2018).

Nota-se no gráfico 1 que $40 \%$ da amostra pesquisada, possui dois cartões de créditos. Para 35\% da amostra os dados apontam para apenas um cartão de crédito. $18 \%$ afirmam possuir três cartões de créditos. Apenas 5,8 \% da amostra afirmou que possui quatro ou mais. A tabela 1 apresenta a frequência de compras realizada com cartão de crédito.

Tabela 1 - Frequência de realização de compras com cartão de crédito

\begin{tabular}{lcc}
\hline \multicolumn{1}{c}{ Respostas } & Relativo (\%) & Absoluto \\
\hline Uma vez ao mês & 12,7 & 13 \\
\hline Duas vezes ao mês & 25,5 & 26 \\
\hline Três vezes ao mês & 25,5 & 26 \\
\hline Quatro vezes ou mais ao mês & 36,3 & 37 \\
\hline Total de entrevistados & 100 & 102 \\
\hline
\end{tabular}

Fonte: Dados obtidos da pesquisa (2018).

Observa-se na tabela 1 que $36,3 \%$ dos pesquisados disseram que realizam compras quatro vezes ou mais ao mês, $25,5 \%$ utiliza o cartão de crédito três vezes ao mês, outros $25,5 \%$ utiliza duas vezes ao mês, somente $12,7 \%$ usa o cartão de crédito apenas uma vez ao mês. De acordo com o último balanço sobre a utilização do cartão de crédito, e dos meios eletrônicos de pagamentos, realizada por Fernando Chacon (2017) para a Associação Brasileira de Cartões de Crédito e Serviços, mostram que o valor 


\section{pontěditora}

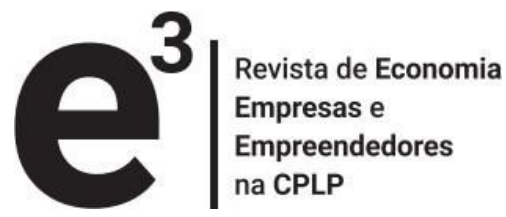

transacionado por cartão de crédito teve um aumento de 12,4\% em relação a 2016, sendo em reais em 2016 o valor de R \$ 749,7 bilhões enquanto em 2017 este valor ficou em R \$ 842,6 bilhões. Foi analisada também a frequência da utilização do cartão, $96 \%$ utilizam cartão todo o mês, 55\% utilizam pelo menos um dia da semana e 58\% usam o parcelamento lojista todo mês.

No gráfico 2 identificou-se se o pagamento de faturas é feito em atraso.

\section{Gráfico 2 - Faturas pagas em atraso}

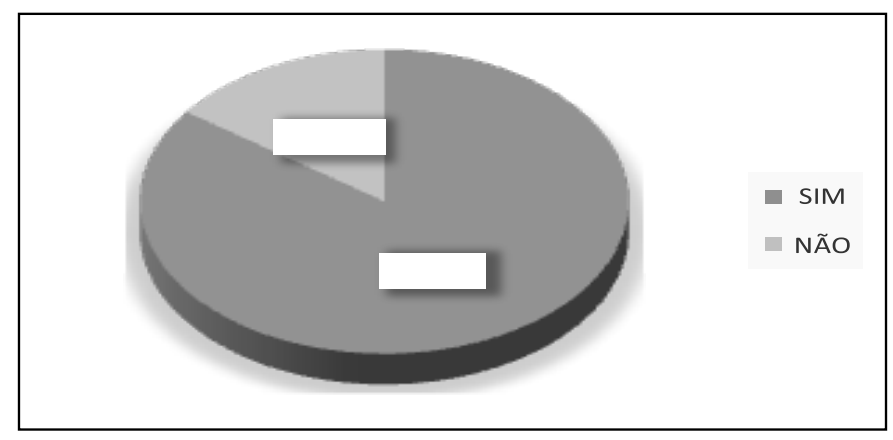

Fonte: Dados da pesquisa (2018).

Nota-se que $84,5 \%$ dos pesquisados pagam suas faturas após o vencimento, mediante esse pagamento em atraso é gerado juros, e desse modo deixa explícito que a inadimplência ocorre quando ao ser ultrapassado o prazo para pagamento da compra realizada, neste há a incidência de juros, estes que são definidos e variados de acordo com a política da administradora do cartão.

"Evidentemente, quanto maior o risco de inadimplência do devedor, ou seja, quanto mais incapaz ele se mostra de efetuar os pagamentos de juros e principal nas datas pactuadas, mais alta se apresenta a taxa de juros exigida da operação" (ASSAF NETO, 2012, p. 81). A tabela 2 exibe o percentual de pessoas que pagam o valor mínimo da fatura do cartão de crédito.

Tabela 2 - Pagamento mínimo da fatura

\begin{tabular}{|c|c|c|}
\hline Respostas & Relativo (\%) & Absoluto \\
\hline Nunca & 35,9 & 37 \\
\hline Raramente & 29,1 & 30 \\
\hline Ás vezes & 31,1 & 32 \\
\hline Sempre & 3,9 & 4 \\
\hline Total de entrevistados & 100 & 103 \\
\hline
\end{tabular}

Fonte: Dados da pesquisa (2018). 


\section{pontěditora}

De acordo com a Tabela 2, 3,95\% afirmaram não realizar o pagamento do valor mínimo da fatura do cartão de crédito. No entanto, cerca de $31,1 \%$ disseram que às vezes efetuam o pagamento mínimo tornando um índice preocupante. $29,1 \%$ responderam que raramente fazem esse tipo de pagamento e apenas 3,9\% desempenham sempre o pagamento mínimo. $\mathrm{O}$ gráfico 3 buscou avaliar quais a primeiras formas de pagamento usadas pelos pesquisados.

\section{Gráfico 3 - Formas de pagamentos mais usadas.}

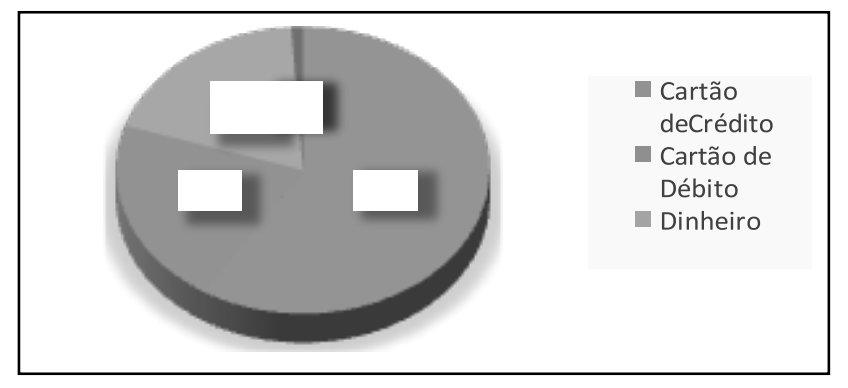

Fonte: Dados da pesquisa (2018).

A maioria dos pesquisados (59\%) afirmou realizar pagamentos de suas compras através do cartão de crédito por falta de dinheiro no ato da compra, $21 \%$ informou fazer os pagamentos no cartão de débito, 19\% efetua o pagamento a vista (dinheiro). Somente $1 \%$ dos pesquisados utiliza carnês e cheque foi nulo. Tal resultado demonstra, que o cheque vem perdendo espaço para outros meios de pagamento como; cartões de créditos e de débito. Em um estudo solicitado pela Associação Brasileira de Cartões de Crédito e Serviços (ABECS) a Tendências Consultorias em 2011, mostra que o crescimento das vendas mediante cartões de crédito, está em plena expansão no Brasil. A preferência por este meio de pagamento dá-se pelas vantagens oferecidas, sendo estas: pagamento de todas as despesas com prazo, parcelamento, conveniência, praticidade em não precisar está com dinheiro em espécie, ou aguardar ter todo o montante para realização das suas compras. 


\section{pontěditora}

O gráfico 4 apresenta os resultados relativos ao motivo pelo qual não se paga a fatura do cartão de crédito.

\section{Gráfico 4 - Motivo para não pagamento da fatura de cartão de crédito}

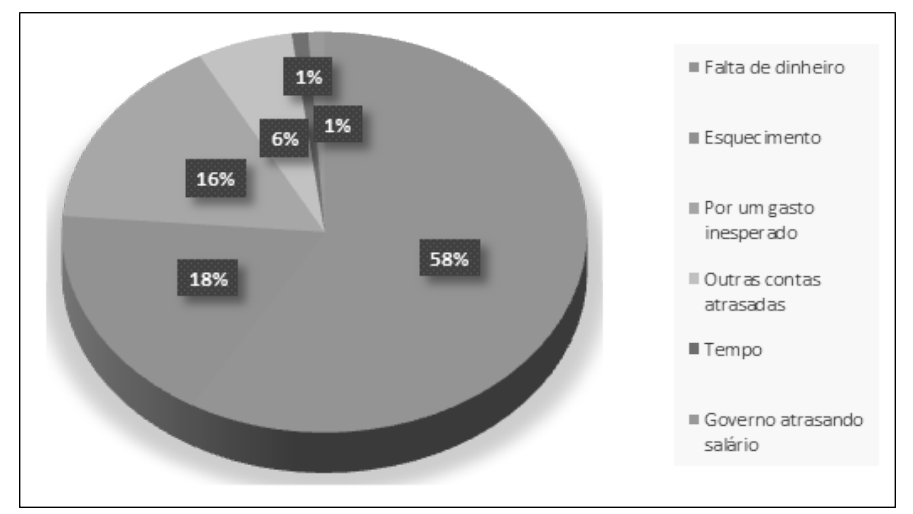

Fonte: Dados da pesquisa (2018).

O resultado aponta que uma grande parte (58\%) dos pesquisados afirmaram que não pagam suas faturas por falta de dinheiro, $18 \%$ declararam que se esquecem de realizar o pagamento, $16 \%$ alegam não pagar as faturas pelo surgimento de um gasto inesperado e $6 \%$ declarou ter outras contas atrasadas.

Quanto à incidência de juros pela falta do pagamento, concorda Assaf Neto (2012, p. 80) que "O juro pode ser entendido como o preço pago pelo aluguel do dinheiro, ou seja, o valor que deve ser pago pelo empréstimo de um capital." Com base nas respostas foi identificado que a maioria dos entrevistados utilizam cartão de crédito, mas que não realiza o pagamento por falta de dinheiro. A tabela 3 apurou o comportamento do consumidor no ato da compra ao perceber que não possui saldo disponível para realizála.

Tabela 3 - No ato da compra perceber que não possui saldo disponível para realizá-la

\begin{tabular}{lll}
\hline \multicolumn{1}{c}{ Respostas } & Relativo (\%) & Absoluto \\
\hline Desiste da compra & 21,9 & 23 \\
\hline Aguarda até a data em que possua este saldo & 28,6 & 30 \\
\hline Busca dinheiro emprestado & 1 & 1 \\
\hline Compra no cartão de crédito mesmo & 44,8 & 47 \\
\hline Procura formas de pagamentos como carnê & 3,8 & 4 \\
\hline Total de entrevistados & 100 & 105 \\
\hline
\end{tabular}

Fonte: Dados da pesquisa (2018). 
Através da pesquisa foi possível observar que $44,8 \%$ dos entrevistados ao perceber no ato da compra que não possui saldo disponível não desistem da compra, utilizam o cartão de crédito assim mesmo; 28,6\% afirmaram que aguarda até a data em que possua este saldo, apenas 21,9\% relata desistir da compra. De acordo com Froemming et al. (2009, p. 19), “Comportamento do Consumidor concentra seus estudos para entender como as pessoas pensam e agem no suprimento de suas necessidades e desejos por meio da atividade do consumo".

O gráfico 5 procurou identificar os motivos pelos quais os pesquisados possuem nome inscrito em algum órgão de proteção ao crédito.

\section{Gráfico 5 - Nome inscrito em algum órgão de proteção ao crédito e seus motivos}

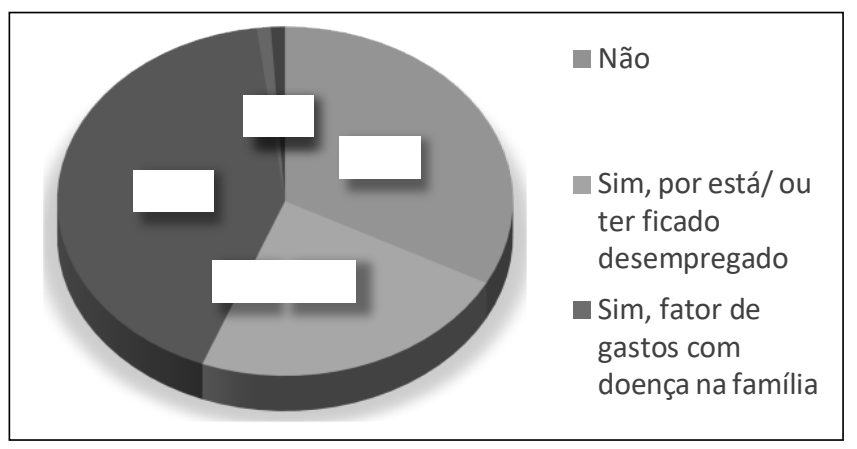

Fonte: Dados da pesquisa (2018).

Nota-se na análise do gráfico 5 que 33\% dos pesquisados não possui o nome em órgãos de proteção ao crédito. No entanto, $23 \%$ afirmam que possui no nome inscrito por estar ou ter ficado desempregado. Cerca de $42 \%$ dos entrevistados assumiram ter o nome escrito em algum órgão de proteção ao crédito por falta de planejamento financeiro.

A falta de planejamento financeiro tem sido apontada como uma das causas de que os consumidores acabarem caindo no endividamento, como publicou a $\mathrm{CDL} / \mathrm{BH}$ "a falta deste tem trazido muitos problemas às famílias, pois elas não têm o hábito de organizarem suas contas" (BASTOS, 2017).

De acordo com Cerbasi (2004 p. 34),

O planejamento financeiro tem um objetivo muito maior do que simplesmente não ficar no vermelho. Mais importante do que conquistar um padrão de vida é mantê-lo, e é para isso que devemos planejar. Os maiores benefícios dessa atitude serão notados alguns anos depois, quando a família estiver usufruindo a tranquilidade de poder garantir a faculdade dos filhos ou a moradia no padrão desejado, por exemplo. 


\section{pontěditora}

A tabela 4 buscou identificar a frequência com que as pessoas ultrapassam o limite do cartão de crédito.

\begin{tabular}{|c|c|c|}
\hline Respostas & Relativo (\%) & Absoluto \\
\hline Nunca & 26 & 27 \\
\hline Raramente & 20,2 & 21 \\
\hline Ás vezes & 42,3 & 44 \\
\hline Sempre & 11,5 & 12 \\
\hline Total de entrevistados & 100 & 104 \\
\hline
\end{tabular}

Constata-se na tabela 4 que $26 \%$ não tem o hábito de gastar além do limite do cartão de crédito, 20,2\% afirma que raramente ultrapassa seu limite do cartão e $11,5 \%$ informou que sempre extrapola nas compras e estoura o limite. Usando o item anterior como comparação exatamente $42,3 \%$ dos entrevistados assumiram ter o nome escrito em algum órgão de proteção ao crédito são exatamente os $42 \%$ que possui o hábito de estourar o limite do cartão de crédito.

O gráfico 6 apurou o comportamento dos consumidores ao encontrar promoções e liquidações em lojas.

Gráfico 6 - Conduta dos pesquisados ao se depararem com promoções, liquidações em lojas

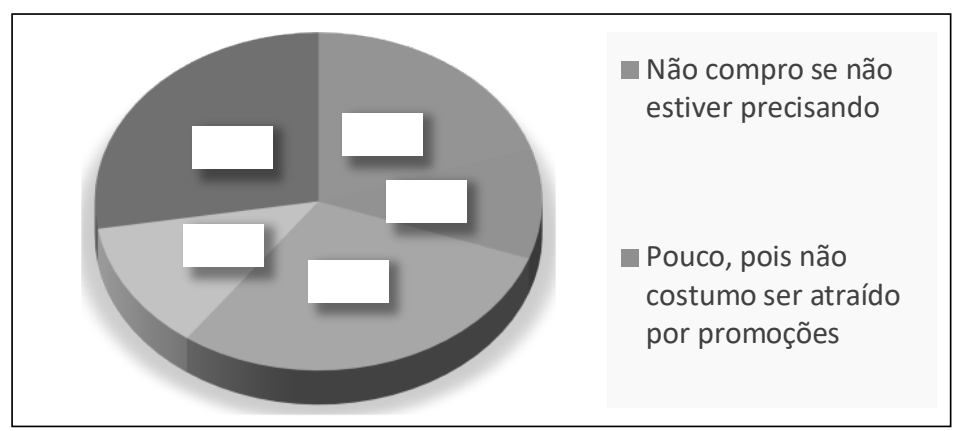

Fonte: Dados da pesquisa (2018).

Conforme observa-se no gráfico $6,30 \%$ dos pesquisados apontam que ao seu deparar com promoções e liquidações possui um comportamento moderado, compram apenas o que atende suas necessidades. $28 \%$ reconhece comprar mesmo sem dinheiro para aproveitar o preço, 20\% alega não comprar se não estiver precisando, $12 \%$ garante 


\section{pontěditora}

comprar apenas se estiver o dinheiro e apenas $10 \%$ afirma comprar pouco, pois não costuma ser atraído por promoções. O gráfico 7 apresenta os resultados referentes ao que geralmente as pessoas mais gastam em seu cartão de crédito.

\section{Gráfico 7 - Gastos frequentes no cartão de crédito.}

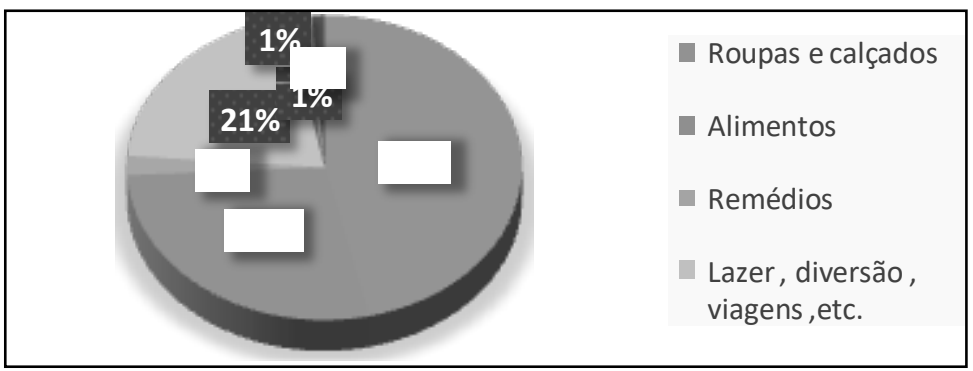

Fonte: Dados da pesquisa (2018).

De acordo com o gráfico 7, a maioria dos pesquisados (46\%) geralmente gasta mais seu cartão com roupas e calçados, $28 \%$ relatou que utiliza mais o cartão de crédito com alimentos e $21 \%$ usa o cartão para o lazer, diversão e viagens. Apenas $2 \%$ gasta o cartão com remédios. O gráfico 8 apresenta o índice da utilização de método de controle de gastos.

Gráfico 8 - utilização de método de controle de gastos.

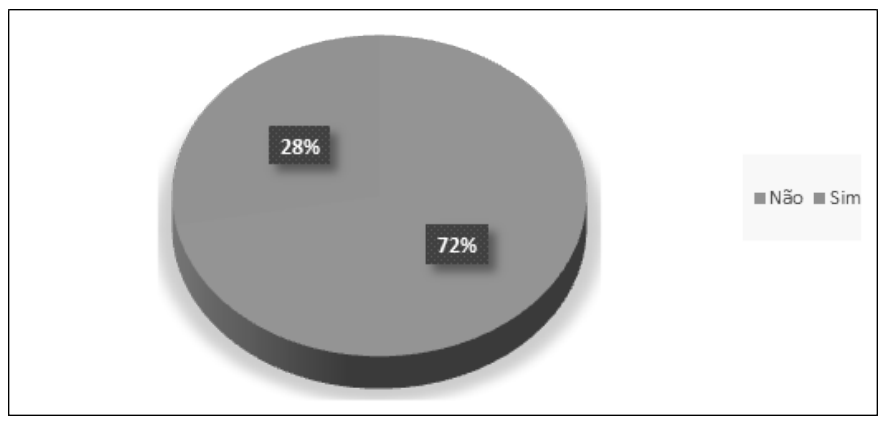

Fonte: Dados da pesquisa (2018).

No gráfico 8 evidencia que $72 \%$ dos pesquisados afirma não utilizar método de controle de gastos, na ausência desses métodos de controle de gastos o risco de inadimplência se torna imenso. De acordo com Rocha (2007), um indivíduo com suas finanças em ordem, tem maior capacidade de tomar decisões e encarar suas adversidades de uma maneira mais positiva. Apenas 28\% utiliza métodos para controlar seus gastos. A tabela 5 exibe o percentual de pessoas que possuem conhecimento de alguma forma de planejamento 


\section{pontěditora}

financeiro.

Tabela 5 - Conhecimento de alguma forma de planejamento financeiro

\begin{tabular}{lll}
\hline \multicolumn{1}{c}{ Respostas } & Relativo (\%) & Absoluto \\
\hline Nenhum conhecimento & 11,4 & 12 \\
\hline Pouco conhecimento & 37,1 & 39 \\
\hline Tenho conhecimento, mas não aplico & 35,2 & 37 \\
\hline Tenho conhecimento e aplico & 16,2 & 17 \\
\hline Total & 100 & 105 \\
\hline
\end{tabular}

Fonte: Dados da pesquisa (2018).

De acordo com a tabela 5, 11,4\% não possui conhecimento de formas de planejamento financeiro, $37,1 \%$ afirma ter pouco conhecimento, $35,2 \%$ possui o conhecimento mais não aplica e apenas 16,2\% tem conhecimento e aplica. A falta de planejamento financeiro tem sido apontada como uma das causas de que os consumidores acabarem caindo no endividamento, como publicou a $\mathrm{CDL} / \mathrm{BH}$ "a falta deste tem trazido muitos problemas as famílias, pois elas não têm o hábito de organizarem suas contas" (BASTOS, 2017).

O gráfico 9 aponta que utilizar um método de planejamento auxilia a melhorar sua vida financeira.

\section{Gráfico 9 - Aplicação do método de planejamento auxilia a vida financeira.}

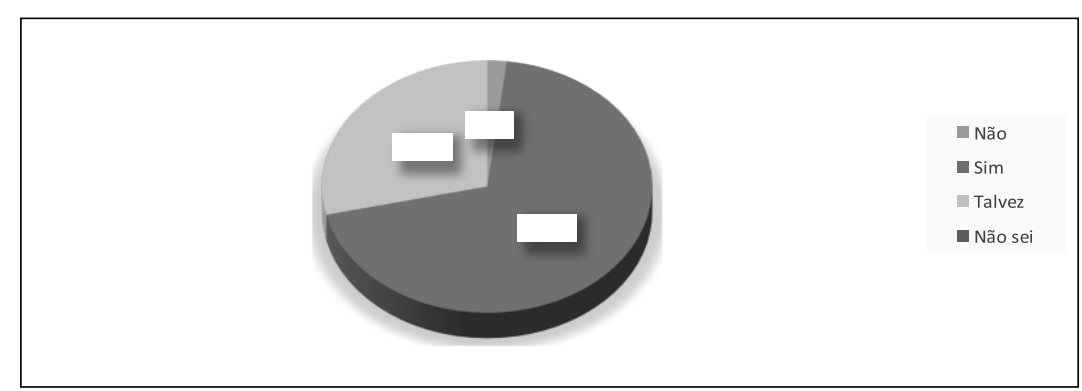

Fonte: Dados da pesquisa (2018).

Nota-se que 69\% dos pesquisados acredita que através da aplicação de um método de planejamento é possível melhorar a vida financeira, 29\% responderam que talvez o método possa ajudar a gerir a vida financeira. E apenas $2 \%$ afirmam que o método não melhora a vida financeira. 
De acordo com Cerbasi (2004 p. 34),

\begin{abstract}
O planejamento financeiro tem um objetivo muito maior do que simplesmente não ficar no vermelho. Mais importante do que conquistar um padrão de vida é mantê-lo, e é para isso que devemos planejar. Os maiores benefícios dessa atitude serão notados alguns anos depois, quando a família estiver usufruindo a tranquilidade de poder garantir a faculdade dos filhos ou a moradia no padrão desejado, por exemplo.
\end{abstract}

A motivação dessa pesquisa fundamentou-se em realizar um estudo das causas de inadimplência de usuários de cartão de credito em Belo Horizonte. O estudo possibilitou conhecer o perfil, as atitudes, o comportamento dos entrevistados, por meio da amostra pesquisada. Os resultados indicaram que grande maioria dos entrevistados possui pouco conhecimento sobre planejamento financeiro que possibilita a inadimplência.

\title{
5 - Conclusão e proposta
}

Com o presente estudo descobriu-se que maioria entrevistada, possui comportamentos comuns como: 36,3 \% tem uma frequência de utilização de cartão de crédito mais de quatro vezes ao mês, $42 \%$ estão ou já tiveram seu nome inscrito em um órgão de proteção ao crédito por falta de planejamento, $46 \%$ utilizam o cartão na maioria das vezes em compras de roupas e sapatos.

Ainda com a pesquisa foi possível analisar que este meio de pagamento influencia a vida de seus usuários, quando permite que os mesmos possuam maior poder de compra, porém nem sempre sendo esta sua real condição de pagamento, por serem em sua grande maioria com pouco conhecimento sobre planejamento financeiro, ou ter conhecimento. Porém não aplicar, torna-se este um meio de grande possibilidade de entrar em inadimplência pelos seus utilizadores.

Tendo visto tal situação, a proposta de controle de gastos é essencial para o público-alvo e entrevistado nesta pesquisa. Existem hoje diversos métodos de controles disponíveis, desde uma planilha de programa da Microsoft o Excel, a aplicativos de celulares, onde é possível lançar seus gastos mensais e ter em mãos o quanto do seu orçamento está comprometido, entre eles: Mobills, Wisecash, Guia de Bolso, Money Manager, 
Organizze, etc; sendo os mesmos gratuitos.

No entanto, apesar de existirem tantas formas de planejamento, ainda fica o questionamento de como lidar com a falta de conhecimento e incentivo das pessoas em iniciar seu planejamento financeiro pessoal? O planejamento financeiro passou a ser uma das matérias inclusas na nova base nacional comum curricular, mas estes ainda enfrentam o desafio de contar com educadores que possuem instrução sobre o assunto para passar, de forma que prepare o aluno para utilizar de modo consciente seu dinheiro.

A importância da difusão deste conhecimento desde cedo, não só prepara alunos a lidarem com o seu bolso, mas também pode contribuir com o planejamento de sua família, fora o impacto que gerará na economia, onde pessoas sabem gastar, compram de uma maneira equilibrada e diminui os índices de inadimplência de várias pessoas e empresas. Mas a qualquer momento da vida, é possível compreender e aplicar o planejamento, o que se percebe é que necessita ser investido em formas mais práticas, dinâmicas e de fácil acesso para a adesão a métodos de controle e prática de um bom planejamento nas diversas classes; aumentar o incentivo a estudos na área de forma a contribuir com ideias que conscientizem a sociedade sobre sua importância, levando-os a compreender o quão benéfico é a realização do planejamento de suas finanças. Dentre as formas de se realizar um planejamento, a nossa proposta é a indicação de um dos aplicativos já citados: o Mobills.

Foi proposto ele por ser um aplicativo gratuito e de fácil acesso, que pode ser instalado em um smartphone, hoje de uso comum das pessoas; estando sempre à mão ele auxilia na falta de tempo em realizar uma planilha e também de lançar todos os gastos. Mesmo que o usuário possua pouco conhecimento, este não terá dificuldades em lançar suas despesas de contas como água, luz e etc; assim como lançar seus gastos com cartão de crédito, obtendo maior controle sobre o quanto do seu orçamento está comprometido, ainda pode-se organizar suas próximas compras, também planejar o pagamento das dívidas em atraso e ocasionalmente sair da inadimplência. 


\section{REFERÊNCIAS}

ABECS, Associação Brasileira de Cartão de Crédito e Serviços. Análise econômica dos benefícios advindos do uso de cartões de crédito débito. São Paulo, 2011 Disponível em:

$<$ http://abecs.org.br/app/webroot/files/media/f/2/1/4a97bc8811e08c52cbff76272e4e0.p df $>$. Acesso em: 18 abr. 2018.

ASSAF NETO, Alexandre. Finanças corporativas e valor. 6. ed. São Paulo: Atlas, 2012.

BACEN, Banco Central do Brasil. Caderno de educação financeira- gestão de finanças pessoais. Brasília, 2013. Disponível em: $<$ https://www.bcb.gov.br/pre/pef/port/caderno_cidadania_financeira.pdf $>$. Acesso em: 03 abr. 2018.

BASTOS, Ana Paula. Perfil do inadimplente Bh, CDL/BH. Belo Horizonte, 2017. Disponível em:

$<$ http://www.cdlbh.com.br/portal/6244/Sugestao_de_Pauta/Perfil_do_Inadimplente_B $\mathrm{H}>$. Acesso em: 5 abr. 2018.

CDL/BH, Câmara de Dirigentes Lojistas. Indicador de inadimplência. Belo Horizonte, 2017. Disponível em: <http://www.cdlbh.com.br/portal/6156/2017/Janeiro>. Acesso em: 5 abr. 2018.

CERBASI, Gustavo. Casais inteligentes enriquecem juntos. São Paulo: Gente, 2004.

CERVO, Amado Luiz; BERVIAN, Pedro Alcino; SILVA, Roberto da. Metodologia científica. 6. ed. São Paulo: Pearson, 2006.

CHACON, Fernando. Números do setor de meios eletrônicos de pagamento, ABECS. São Paulo, 2017. Disponível em:

$<$ http://abecs.org.br/app/webroot/files/media/0/8/a/4f5663d03ef150e15d87f9d65df68.p df $>$. Acesso em: 18 abr. 2018.

CNC, Confederação Nacional do Comércio de Bens, Serviços e Turismo. Pesquisa de endividamento e inadimplência do consumidor. 2018. Disponível em:

$<$ http://cnc.com.br/central-doconhecimento/pesquisas/economia/pesquisa-de-

endividamento- $\quad$ e-inadimplencia-do-consumidor-1"traldoconhecimento/pesquisas/economia/pesquisa-de- endividamento-e-inadimplencia-doconsumidor-1>. Acesso em: 20 mar. 2018.

FROEMMING, Lurdes Marlene et al. Comportamento do consumidor e do comprador. Unijuí. Ijuí , 2009 Disponível em:

$<$ http://bibliodigital.unijui.edu.br:8080/xmlui/bitstream/handle/123456789/170/Compo rtamen

to $\% 20 \mathrm{do} \% 20$ Consumidor $\% 20 \mathrm{e} \% 20 \mathrm{do} \% 20$ Comprador.pdf?sequence=1"3456789/170/

Compo

rtamento $\% 20 \mathrm{do} \% 20$ Consumidor $\% 20 \mathrm{e} \% 20 \mathrm{do} \% 20 \mathrm{Comprador}$.pdf? sequence $=1>$. 


\section{pontěditora}

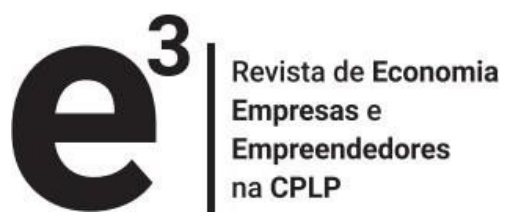

Acesso em: 10 abr. 2018.

GITMAN, Lawrence J. Princípios da administração financeira. São Paulo: Pearson, 2017.

IBGE. Instituto Brasileiro de Geografia e Estatística. Panorama da população de Belo Horizonte, 2017. Disponível em: <https://cidades.ibge.gov.br/brasil/mg/belohorizonte/panorama>. Acesso em: 1 maio 2018.

KUNKEL, Franciele Ines Reis; VIEIRA,Kelmara Mendes; POTRICH,Ani Caroline Grigion. Causas e Consequências da dívida no cartão de crédito. Revista de Administração-RAUSP. São Paulo, v.50, n.2, p.169-182, abr./maio/jun, 2015. Disponível em:

$<$ http://www.scielo.br/pdf/rausp/v50n2/0080-2107-rausp-50-02-

0169.pdf"ausp/v50n2/0080- 2107-rausp-50-02-0169.pdf>.Acesso em: 05 abr. 2018

LAPORTA, Taís. Portal de notícias G1. Classes D e E são 80\% dos inadimplentes no cartão de crédito; veja dicas para não se tornar uma vítima. 2017a. Disponível em $<$ https://g1.globo.com/economia/educacao-financeira/noticia/classes-d-e-e-sao-80-dosinadimplentes-no-cartao-de-credito-veja-dicas-para-nao-se-tornar-uma-vitima.ghtml $>$. Acesso em: 26 mar. 2018.

LAPORTA, Taís. Portal de notícias G1. Inadimplência no cartão cresce mesmo após nova regra do rotativo. 2017b. Disponível em: <https://g1.globo.com/economia/seudinheiro/noticia/inadimplencia-no-cartao-cresce-mesmo-apos-nova-regra-dorotativo.ghtml>. Acesso em: 26 mar. 2018.

MAIA, Andrea do Socorro Rosa Silva. Inadimplência e recuperação de créditos. Londrina, 2007. Disponível em:

$<$ http://www.lume.ufrgs.br/bitstream/handle/10183/13938/000649712.pdf $>$. Acesso em: 11 abr. 2018

MARCONI, Marina de Andrade; LAKATOS, Eva Maria. Fundamentos de metodologia científica. 6. ed. São Paulo: Atlas, 2009.

SERASA EXPERIAN. Sobre o Serasa experian. Disponível em:

$<$ https://www.serasaexperian.com.br/sobre>. Acesso em: 08 maio 2018.

SPC Brasil, Serviço de Proteção ao Crédito. Conheça o SPC Brasil. Disponível em: $<$ https://www.spcbrasil.org.br/institucional/spc-brasil >. Acesso em: 08 maio 2018.

\section{(cc) EY-NC-SA}

O trabalho t $^{3}$ - Revista de Economia, Empresas e Empreendedores na CPLPestá licenciado com uma Licença Creative Commons - Atribuição-NãoComercial-Compartilha Igual 4.0Internacional. 